\title{
Dentist innovation awards open for entries
}

Shining examples of initiatives that have improved children's oral health can now be recognised as the British Society of Paediatric Dentistry has opened its annual Outstanding Innovation Award for entries.

The award, now in its second year, was created to celebrate inspiring and innovative initiatives to improve oral health of children in the UK and publicise these to encourage, promote and disseminate good practice.

The winner in 2018 was dentist Ben Underwood for his tooth-brushing app BrushDJ to inspire improved tooth brushing amongst children. The first prize for the award is the opportunity to speak at BSPD's conference and receive a certificate.

At the 2018 conference held on 11-14 September 2018 in Dundee, Underwood outlined the background to the development of the app which has now been downloaded in 199 countries.

Underwood told the conference that because the majority of people own Smart phones, he was confident that mobile phone use would continue to accelerate and a free app with music could have universal appeal.

He also made the free app accessible to all including blind or low vision users and those with dyslexia.

Underwood was an inaugural NHS Innovation Accelerator Fellow and BrushDJ is the only dental app in the NHS digital library. It has won multiple awards and he continues to evolve content and extend access to free music.

Entries for the 2019 award can be on paper or in electronic or poster format and there is no word limit. Pictures which illustrate the project are welcome but not essential. Judging will be undertaken by BSPD's Executive Committee at its February meeting.

Claire Stevens, media spokesperson for BSPD, said: 'The award celebrates the work of BSPD members and anybody with an interest in children's oral health can join. After two great winners in 2017 and 2018 we are really excited to see who enters next year. We are committed to supporting innovation in children's oral health.'

- More details are available at https://www. bspd.co.uk/Professionals/Awards-and-Prizes. BSPD members are asked to submit entries to administrator@bspd.co.uk by 5pm on 31 January 2019.

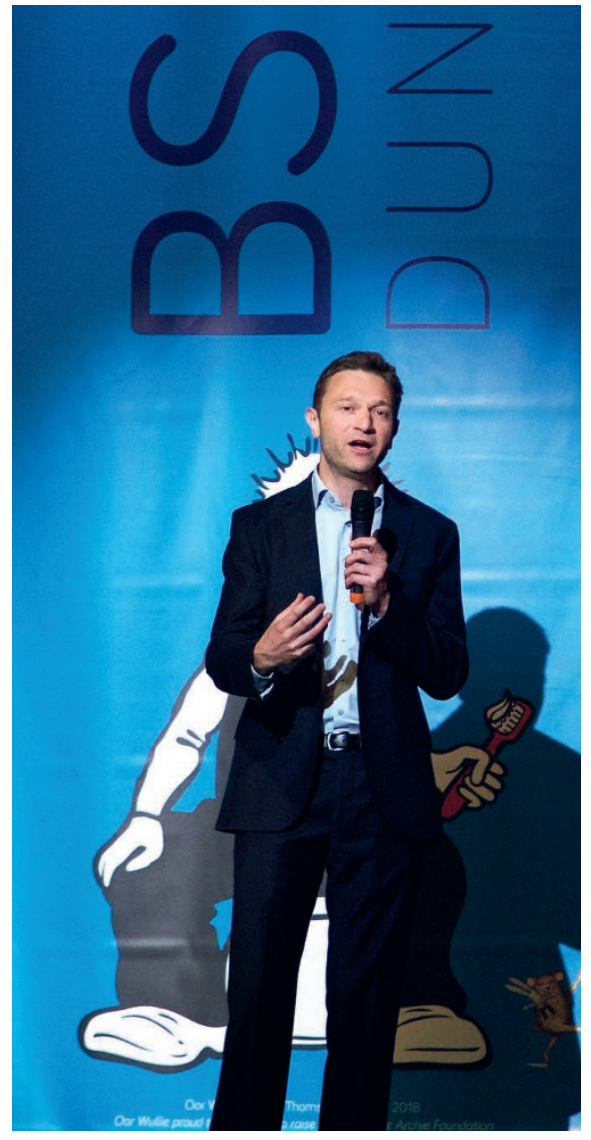

\section{Almost $90 \%$ of dentists have fears of being sued by patients}

As many as nine out of ten (89\%) of 1,100 dentists surveyed recently said they were increasingly concerned that they would be sued by patients.

The survey was carried out by Dental Protection - part of the Medical Protection Society, the protection organisation for dentists, doctors, and healthcare professionals - and involved a survey that gathered 1,129 responses from British dentists.

Responses also showed that around three quarters (74\%) of dentists felt that the fear of being sued was affecting the services they believed they were able to offer, while $64 \%$ of respondents felt that the fear of being sued had resulted in them making more referrals.

Nearly all respondents (98\%) believed that society was becoming more litigious and $79 \%$ of them were concerned about the impact this had on their welfare and the way they practised, with $77 \%$ of respondents admitting that the fear of being sued had caused them stress or anxiety.

Dental Protection said the fear was not without foundation because $43 \%$ of the public believe there are now more marketing campaigns by 'No Win No fee' firms compared to five years ago, according to a separate YouGov survey of 2,000 people.

Key areas where Dental Protection was seeing claims included the diagnosis of caries, periodontal disease and the outcome of endodontic treatment. Issues around consent also often featured in clinical negligence claims.

Raj Rattan, Dental Director at Dental Protection, said: 'Dentists work in an increasingly challenging environment. It is worrying that three out of four full time general dental practitioners fear being sued by patients and understandably this will undoubtedly impact on the way they practise and add to already high stress levels.

'Without proper consent and comprehensive, well organised records, a dentist will be severely disadvantaged in defending any allegations that may surface at a later date. Inadequate clinical records will make the case less defensible and often compromise the final outcome. Dental Protection can provide members with further advice and guidance.

'We always encourage dentists to explain the costs, risks and benefits of all the treatment options and ensure that the patient has a clear understanding of the planned procedure so that patient expectations can be met. Where a patient expresses dissatisfaction about any aspect of their care, dentists should take this as an opportunity to resolve the issue promptly to the patient's satisfaction.

'At Dental Protection we continue to support our members by offering advice and guidance on how to manage the complaint and importantly how to contain the risk of escalation. 